\title{
Metastasis of Mammary Carcinoma in Bitches: Evaluation of the Sentinel Lymph Node Technique
}

\author{
Hugo Enrique Orsini Beserra1, Fabrizio Grandi1,2, Rozany Mucha Dufloth², \\ Luiz Gonzaga Porto Pinheiro ${ }^{3}$, Hélio Amante Miot',

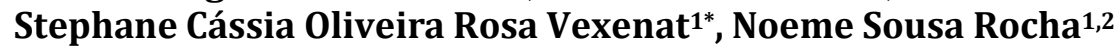

\begin{abstract}
${ }^{1}$ Department of Veterinary Clinics, Service of Veterinary Pathology, School of Veterinary Medicine and Animal Science, Universidade Estadual Paulista (UNESP), Botucatu, Brazil

${ }^{2}$ Department of Pathology, Botucatu Medical School, Universidade Estadual Paulista (UNESP), Botucatu, Brazil

${ }^{3}$ Department of Surgery, Medical School, Universidade Federal do Ceará (UFC), Fortaleza, Brazil

${ }^{4}$ Department Dermatology, Botucatu Medical School, Universidade Estadual Paulista (UNESP), Botucatu, Brazil Email: enriqueorsini@gmail.com,fgrandivet@gmail.com,dufloth@gmail.com, luizgporto@uol.com.br, heliomiot@fmb.unesp.br, "Stephanevexenat@gmail.com,rochanoeme@fmvz.unesp.br
\end{abstract}

Received 20 January 2016; accepted 2 April 2016; published 8 April 2016

Copyright (C) 2016 by authors and Scientific Research Publishing Inc.

This work is licensed under the Creative Commons Attribution International License (CC BY). http://creativecommons.org/licenses/by/4.0/

(c) (7) Open Access

\begin{abstract}
In recent years the development of extremely accurate techniques for the removal of lymph nodes has been seen, such as the Sentinel Lymph Node Biopsy (SLNB) technique. The technique is based on the staggered progression occurring in the lymphatic drainage of neoplasias, and is currently the main prognostic and diagnostic factor in women suffering from mammary carcinoma. This research aims at assessing the sentinel lymph node biopsy accuracy in female dogs suffering from mammary carcinoma. Forty-one dogs with cytological diagnosis of the tumor were used in the research. After injecting a Patent Blue V dye, mastectomy was conducted jointly with lymphadenectomy (for both sentinel and non-sentinel lymph nodes). The material was then serially sectioned and microscopically evaluated by routine H\&E stain and immunohistochemical study with the markers for pancytokeratin AE1/AE3 and myoepithelial cells CK14. The study revealed that 46.3\% $(19 / 41)$ of the animals presented nodal metastasis. The sensitivity and specificity values found for SLNB were respectively $89.5 \%$ and $100 \%$, with a kappa coefficient of 0.90 and $p<0.0001$. Therefore, the SLNB technique offers high sensitivity in the early detection of metastases, allowing higher precision in the staging of oncological patients and, therefore, offering higher chances of survival.
\end{abstract}

\section{Keywords}

Metastasis, Sentinel Lymph Node, Mammary Neoplasia, Patent Blue, Female Dog

\footnotetext{
${ }^{*}$ Corresponding author.
}

How to cite this paper: Beserra, H.E.O., Grandi, F., Dufloth, R.M., Pinheiro, L.G.P., Miot, H.A., Vexenat, S.C.O.R. and Rocha, N.S. (2016) Metastasis of Mammary Carcinoma inBitches: Evaluation of the Sentinel Lymph Node Technique. Advances in Breast Cancer Research, 5, 58-65. http://dx.doi.org/10.4236/abcr.2016.52006 


\section{Introduction}

Nodal metastasis is one of the key prognostic factors in both women and female dogs suffering from mammary neoplasias, being directly related to survival. In addition, they represent the first phase of the tumor's long range spreading [1]. Analysis of the lymph nodes is, therefore, one of the most relevant factors for staging mammary carcinoma in both species [2].

Despite awareness regarding mammary lymphosomes, which are regional lymph drainage sites, several studies have shown that the presence of tumors may significantly alter the lymphatic direction as animals carrying mammary neoplasia undergo lymphatic reconfiguration due largely to the presence of prolymphangiogenic cytokines in the tumor's location [2]-[4].

In the 1970s, the concept of sentinel lymph node (SLN) was introduced for humans, being defined as the first lymph node in a regional lymph node chain that received lymph from a primary tumor. It is, therefore, the first to metastasize the tumor and its biopsy accurately reveals the nodal "status". Accordingly, if the sentinel lymph node biopsy (SLNB) does not reveal the presence of cancer cells, the remaining nodes in the chain will also show a negative result, indicating the absence of lymphatic metastasis [5] [6].

The absence of metastasis in the SLN of women carrying mammary carcinoma is in agreement with the results from the remaining regional lymph nodes in almost $100 \%$ of the cases [7].

As it is not necessary to remove the whole lymphatic chain, there is almost no risk of a lymphedema, appearing and maintaining the success rates established on the prognosis. In addition, the SLNB allows an early diagnosis of metastases, aiding the therapeutic approach and increasing the treatment's success chances [8].

Upon the introduction of this procedure in surgical practice, lymph node micrometastases started to be more commonly detected. This happens because the pathologist can focus on inspecting a single or few lymph nodes, resulting on more thorough searches for metastases. In addition, the smaller quantity of material allows for a larger number of sections, which increases the diagnostic efficiency of the technique [9].

This study aims at assessing the accuracy of the sentinel lymph node biopsy technique in the detection of metastases in female dogs carrying mammary carcinoma.

\section{Material and Methodology}

\subsection{Patients}

Forty and one female dogs were used for this study with no restrictions regarding age, reproductive status and breed. The patients were evaluated by anamnesis, physical examination, complete blood count, biochemical hepatic and renal profile, chest radiography, abdominal ultrasound and fine-needle aspiration of the mammary tumors.

The selection criteria were the absence of abnormalities in the aforementioned examinations and absence of treatments with progestogens (or other hormones).

\subsection{Cytopathological Evaluation of the Neoplasia}

All tumors underwent fine-needle aspiration cytology (FNAC) as per the technique described by [10].

From the material collected, four microscope slides were mounted for each sample, three of which underwent dry fixation in 95\% methyl alcohol for five minutes and stained according to Giemsa's method. The remaining slide was fixated in 95\% ethyl alcohol and then stained following Papanicolaou's technique.

The neoplasias were classified by optical microscopy according to the nuclear cytomorphological and cytoplasmatic malignancy criteria described by [10].

Only animals with a cytological diagnosis of mammary carcinoma were selected for the next stages.

\subsection{Identification of Sentinel Lymph Nodes}

The tumors were divided into equal quarters. During the preoperative, one quarter of the total volume of Patent Blue V 2.5\% (Guerbert ${ }^{\circledR}$ ) was administered in the superficial intradermal peritumoral region at a concentration of $2 \mathrm{mg} / \mathrm{kg}$ [11].

After five minutes, the lymphatic drainage system of each tumor was identified by a visual inspection of the skin, characterized by a blue color in the superficial dermal lymphatic vessels. The drainage routes were visualized and anatomical location corresponding to the sentinel lymph node (SLN) was identified (Figure 1). The 


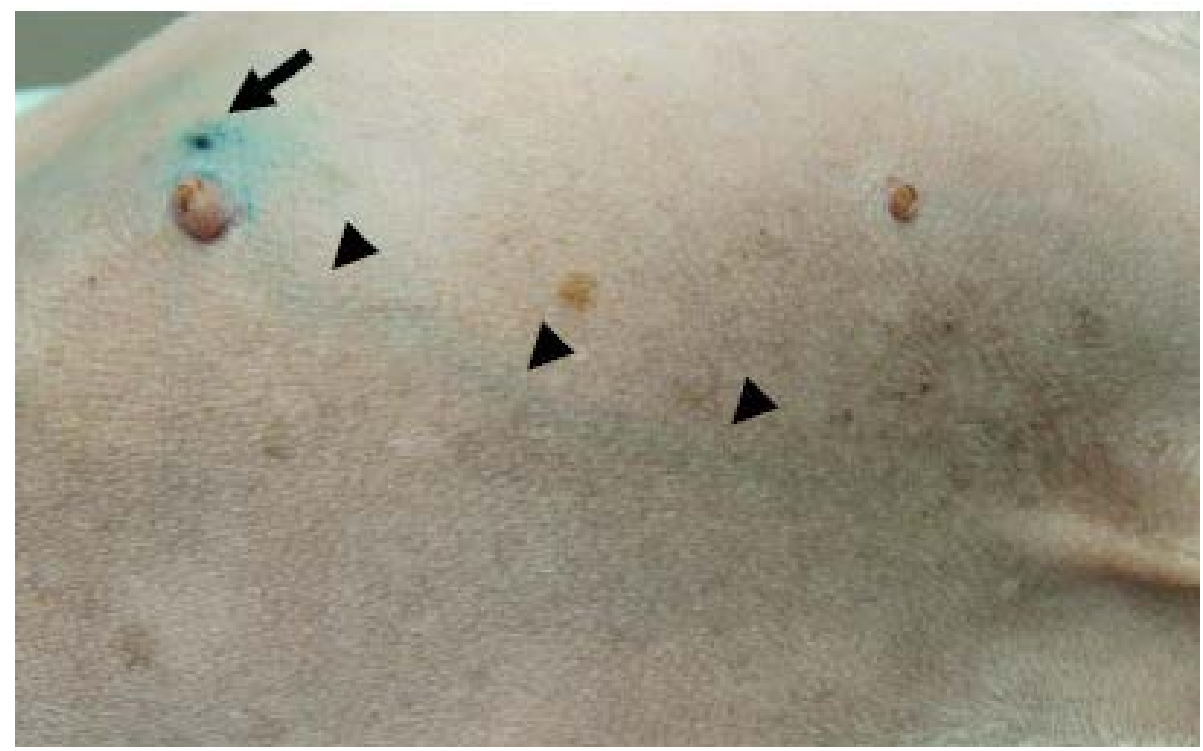

Figure 1. Injection site of vital dye Patent Blue V 2.5\% (Guerbert ${ }^{\circledR}$ ) (arrow). Note the drain region, below the inoculation site toward sub-axillary region (arrohead).

indicated location underwent a simple incision for direct visualization of the SLN stained in blue. All marked SLNs underwent lymphadenectomy followed by unilateral mastectomy. The sentinel lymph nodes and the mammary lymph node chain were identified and fixated in a $10 \%$ formaldehyde solution for 48 hours.

\subsection{Sample Processing}

The representative areas for each tumor were collected according to [12]. Thereafter, a thorough inspection of the surgical piece was conducted, focusing on the surrounding adipose tissue and aiming at identifying the remaining lymph nodes.

Initially, the lymph nodes were transversally cleaved in standardized intervals of $2 \mathrm{~mm}$ across their whole extension, as per the technique described by Schuman et al. (2011). The fragments were then set in individual histological cassettes, undergoing dehydration, clearing and paraffin inclusion [13].

The blocks were then serially sectioned resulting in eighteen $4 \mu \mathrm{m}$ slides. For each section selected for the study, the following 10 sections were discarded, as advocated by [14].

The sections selected for the study were serially numbered from 1 to 15 . Sections 4 , 8 and 12 were made in duplicate for the immunohistochemical study described below. The remaining sections were stained by Hematoxylin and Eosin.

Under optical microscopy, the lymph nodes were classified as positive (for the presence of metastasized cells or groups of cells) and negative (for the absence of metastasized cells or groups of cells).

The largest metastasized area of each lymph node was measured using freeware Image $\mathbf{J}^{\circledR}$ and, according to its size, classified as macrometastasis $(\geq 2 \mathrm{~mm})$, micrometastasis $(0.2-2 \mathrm{~mm})$ or isolated cells $(<0.2 \mathrm{~mm})$ [15].

\subsection{Immunohistochemical Study of Tumors and Lymph Nodes}

The antibodies anti-pan-cytokeratin (AE1/AE3, mouse, Dako ${ }^{\circledR}$, EUA) and anti-cytokeratin 14 (CK14, mouse, Abcam $^{\circledR}$, UK) were used, as suggested by [16].

The histological sections (test and control) were mounted on microscope slides which were silanized $\left(\right.$ Starfrost $\left.{ }^{\circledR}\right)$ and dewaxed in an oven at $60^{\circ} \mathrm{C}$ for an hour, undergoing, then, three xylene baths, each lasting for five minutes.

Afterwards, the sections were hydrated in decreasing concentrations of ethyl alcohol and washed in running water. The slides were put through antigen recovering triggered by heat on a citrate buffer $(\mathrm{pH} 6.0)$ at $125^{\circ} \mathrm{C}$ for 30 seconds and then spent 30 seconds at a Dako Cytomation Pascal ${ }^{\circledR}$ pressure chamber at a temperature of $90^{\circ} \mathrm{C}$. They then cooled at room temperature for 20 minutes. 
The dilutions used were 1:200 for AE1/AE3 and 1:400 for CK14. The slides were incubated overnight in a moist chamber at $4^{\circ} \mathrm{C}$. The detection system used was Novolink ${ }^{\circledR}$ (Novacastra Laboratories, Newcastle, UK) and the chromogen used was 3, 3' diaminobenzidine (DAB), Dako.

Between each of the aforementioned stages, the sections were vigorously washed with TRIS base solution of pH 7.4. The nuclear counterstaining was conducted with Harris' Hematoxylin.

\section{Results}

The age group of the dogs in the study varied from 5 to 14 years old, averaging 10.3 years old.

Two of the dogs in the study presented tumors in more than one mammary gland, totaling 43 tumors.

Regarding the affected mammary gland, the study noticed a $72.1 \%$ (31/43) preponderance in the caudal abdominal and inguinal pairs.

None of the animals in the study presented any collateral or adverse effect, nor any complications arising from the dye or from the lymphadenectomy technique.

During the study, 138 lymph nodes were assessed, around 3.4 (2 - 7 lymph nodes) per animal. Of those, 42.7\% (59/138) were marked by a contrasting material, averaging 1.4 sentinel lymph nodes per animal.

The preferential drainage locations were the subaxillary and ipsilateral inguinal regions, occurring in $89 \%$ of the cases. In 13 (31.7\%) animals, the drainage occurred in more than one location.

In all cases studied, at least one lymph node was found marked in blue.

The rate of animals which presented nodal metastasis by immunohistochemical marking was 46.3\% (19/41), of which 17 were found in sentinel lymph nodes and 2 in non-sentinel lymph nodes.

The validity of the SLNB technique with exclusive usage of patent blue was determined by assessing the sensitivity and specificity values, $89.5 \%$ and $100 \%$ respectively, as well as positive and negative predictive values, respectively $100 \%$ and $91.7 \%$. The accuracy of the technique was $95.7 \%$, with a kappa coefficient of 0.90 and $\mathrm{p}$ $<0.0001$.

Compared to the immunohistochemical study, the H\&E stain presented sensitivity of $94.7 \%$ and specificity of $100 \%$ for the detection of nodal metastases sources, accuracy of $97.5 \%$, as well as positive and negative predictive values of $100 \%$ and $95.6 \%$ respectively.

\section{Considerations}

The SLNB technique is the most important breakthrough of recent years in the surgical treatment of mammary carcinoma in women, as it offers conservative procedures and high diagnostic accuracy.

Clinical studies comparing radical axillary lymphadenectomy to SLNB show that the latter is a safe and efficient procedure, minimizing risks and maximizing the detection of nodal metastases, which is the main predictive factor of systemic disease [8].

In spite of several studies and broad usage in human medicine, the SLNB technique is still little known in veterinary medicine. From the first studies conducted by [17], which showed the method's efficiency for detecting mammary lymph nodes in female dogs, the technique has been used experimentally in canines, albeit timidly, in other anatomical locations, such as the vulva and the stomach [18] [19].

The absence of adverse effects and post-operative complications in this study is in agreement to what is shown in the literature concerning human females, in which descriptions of hypersensitivity to the contrasting substance are rare, occurring in about $0.34 \%$ of the cases. This fact attests to the superiority of this dye as opposed to other markings [20].

The preponderance of carcinomas in mixed tumors has also been reported in epidemiologic studies, occurring together with solid and tubular carcinoma. [12] reported an occurrence rate as high as $66 \%$ for mixed tumors in canine mammary neoplasias.

Despite the importance of this entity to the animal, many pieces of information regarding its development and biology still lie in obscurity [21].

On the other hand, solid carcinomas are common tumors in dogs, presenting an aggressive behavior, often spreading the metastasis to distant locations and presenting low chance of survival without the disease [21] [22].

The use of unilateral radical mastectomy also allows a thorough macroscopic inspection of the surgical specimen, aiding in the visualization of milimetric lymph nodes.

In addition, it is know that the presence of a mammary tumor causes a significant local lymphatic change, as 
the VEGF-c factor expression by the cancer cells results in a reconfiguration of lymph nodes and in the establishment of new drainage sites, as shown in both humans and canines [23]-[25].

For this reason, it is also possible to mark contralateral lymph nodes or lymph nodes belonging to different lymph node basins, as observed in 13 animals involved in the study, involving the cranial abdominal, caudal abdominal and inguinal mammary glands.

This has been noted by several authors, who point to the increase of this occurrence in the cranial abdominal mammary gland, where there are lymphatic anastomoses, which results in an increased metastasis risk [26] [27].

These findings are in agreement with reports by [28], which note a classical drainage pattern, possessing predetermined drainage sites, such as the lymphosomes. In their study, however, no dye or contrast was used, considering only the topographic correlation between neoplasia and lymph node as a lymphadenectomy parameter.

When a parallel is made with studies conducted in human females, our research found a larger number of sentinel lymph nodes than what is described in the literature. This can be justified by the intersections of lymphatic canaliculi that exist between the five mammary glands, which results in a larger drainage area and, therefore, in a larger number of stained lymph nodes [3] [27].

The presence of metastasized cells in non-stained lymph nodes is also reported in women. These cases are associated to the later stages of the lymphatic spreading, in which the cellular proliferation blocks the lymphatic flow, making it impossible for the marker to reach the drainage site (Figure 2), as observed in one of our study's cases [29].

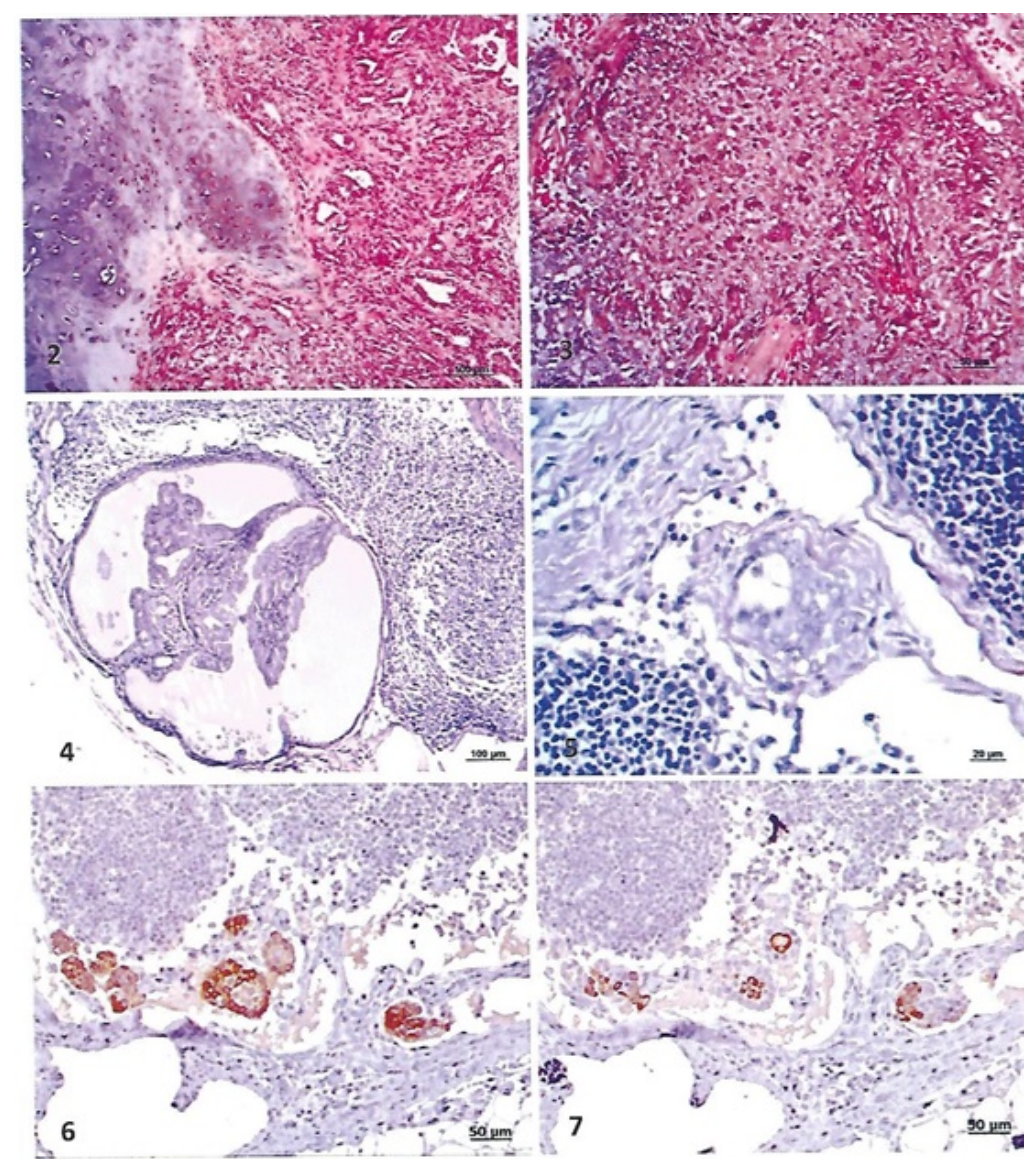

Figure 2. (2): Photomicrograph showing neoplastic proliferation of carcinomatous cells and typical chondroid metaplasia (HE, 10X Obj). (3): Photomicrograph showing carcinomatous cells which are observed in solid arrangement (HE, 20X Obj). (4): Photomicrograph of sentinela lymph node metastatic focus of neoplastic cells in papillary cystic arrangement (HE, 10X Obj). (5): Photomicrograph of lymph node plastic cluster obstructing the lumen of the lymphatic vessel (HE, 20X, Obj). (6): Metastatic cells in the sentinela lymph node showing specific staining for AE1/AE2 (DAB, 20X Obj). (7): Metastatic cells showing specific staining for CK14 (DAB, 20X Obj). 
The observed lymph node positivity rate was higher than the one reported in the literature. Recent studies report a positivity rate of $28.8 \%$ [15].

According to [16], the low rate of nodal metastases is related to mistakes in locating the lymph nodes to be drained as well as to using inadequate histological techniques for metastasis research, which is one of the main factors for the difficulty in establishing a prognosis for animals with mammary cancer.

Despite the lack of consensus regarding the best technique for anatomopathological analysis of the lymph nodes, the inclusion of the whole piece, coupled with the serial sections, allows for the inspection of a larger nodal area, which increases the examination's sensitivity.

Even though the usage of immunohistochemical studies in the anatomopathological diagnosis routine is still low, our study show that its use avoids the occurrence of false-positive results. As happens in human medicine, some studies report the use of the immunohistochemical technique for detecting hidden metastases or, in other words, small cancer cell groups or units which are hard to be seen in common stains [16] (Figure 2).

It is worth noting that the prognostic value of micrometastases for dogs is still unknown, further solidifying the importance of the immunohistochemical diagnosis so that precise data is gathered for future evaluation, providing hitherto unknown information [16] [30].

\section{Conclusions}

Therefore, it is evident that the SLNB is capable of efficiently predicting the nodal status of the patient by means of a simple protocol, as happens in humans.

At least one sentinel lymph node was found in each animal participating in the study, which attested to the efficiency of Patent Blue $\mathrm{V}$ and to the possibility of frequent use of the technique.

The values found for sensitivity, positive predictive value and negative predictive value were similar, and sometimes superior, to those described in human medicine. This indicates that the SLNB technique is a safe method for nodal staging of female dogs carrying mammary carcinoma.

Despite the high sensitivity found in the study, the exclusive usage of routine Hematoxylin \& Eosin stain may make it harder to identify isolated metastasized cells, which leads to false-negative diagnoses.

\section{References}

[1] Quadros, I.G.A. and Gebrim, L.H. (1976) A Pesquisa do linfonodo sentinel para o cancer de mama na prática clínica do ginecologista brasileiro. Revista Brasileira de Ginecologia e Obstetrícia, 29, 158-164.

[2] Matos, A.J.F., Baptista, C.S., Gartner, M.F. and Rutteman, G.R. (2012) Prognostic Studies of Canine and Feline Mammary Tumours: The Need for Starndardized Procedures. The Veterinary Journal, 193, $24-31$. http://dx.doi.org/10.1016/j.tvjl.2011.12.019

[3] Patsikas, M.N., Karayannopolou, E., Kaldrymidoy, L.G., Papazoglou, P.L., Tzegas, S.I., Tziris, N.E., Kaitizi, D.G., Dimitriadis, A.S. and Dessiris, A.K. (2006) The Lymph Drainage of the Neoplastic Mammary Glands in Bich: A Lymphographic Study. Anatomia, Histologia, Embryologia, 35, 228-234. http://dx.doi.org/10.1111/j.1439-0264.2005.00664.x

[4] Suami, H., Yamashita, S., Soto-Miranda, M.A. and Chang, D.W. (2013) Lymphatic Territories (Lymphosomes) in a Canine: Na Animal Model for Investigation of Postoperative Lymphatic Alterations. Plos ONE, 24, e69222. http://dx.doi.org/10.1371/journal.pone.0069222

[5] Sakorafas, G.H. and Peros, G. (2007) Sentinel Lymphnode Biopsy in Breast Cancer: What a Physician Should Know, a Decade after Its Introduction in Clinical. European Journal of Cancer Care, 16, 318-321. http://dx.doi.org/10.1111/j.1365-2354.2006.00762.x

[6] Kelley, M.C., Hansen, N. and Mcmasters, K.M. (2004) Lymphatic Mapping and Sentinela Lymphadenectomy for Breast Cancer. American Journal of Surgery, 188, 49-61. http://dx.doi.org/10.1016/j.amjsurg.2003.10.028

[7] Zengel, B., Yararbas, U., Sirinocak, A., Ozkok, G., Denecli, A.G., Postaci, H. and Uslu, A. (2013) Sentinel Lymphnode Biopsy in Breast Câncer: Review on Various Methodological Approaches. Tumori, 99, 149-153.

[8] Giuliano, A.E., Hunt, K.K., Ballman, K.V., Beitsch, P.D., Whitworth, P.W., Blumencranz, P.W., et al. (2011) Axilary Dissection vs. No Axilary Dissection in Women with Invasive Breast Cancer and Sentinela Node Metastasis: A Randomized Clinical Trial. Journal of the American Medical Association, 305, 569-575.

http://dx.doi.org/10.1001/jama.2011.90 
[9] Veronesi, U., Paganelli, G., Viale, G., Galimberti, V., Luini, A., Zurrida, S., et al. (1999) Sentinel Lymphnode Biopsy and Axillary Dissection in Breast Cancer: Results in a Large Series. Journal of National Cancer Institute, 91, 368-373. http://dx.doi.org/10.1093/jnci/91.4.368

[10] Raskin, R.E. and Meyer, D.J. (2010) Canine and Feline Cytology: A Color Atlas and Interpretation Guide. $2^{\mathrm{a}}$ Edition, Elsevier, Missouri, 450 p.

[11] Pinheiro, L.G.P., Oliveira Filho, R.S., Vasques, P.H.D., Filgueira, P.H.O., Aragão, D.H.P., Barbosa, P.M.E., Beserra, H.E.O. and Cavalcante, R.V. (2009) Hemosiderin. A New Marker for Sentinel Lymph Node Identification. Acta Cirurgica Brasileira, 24, 432-436. http://dx.doi.org/10.1590/s0102-86502009000600002

[12] Cassali, G.D., Gobbi, H., Malm, C. and Schitt, F.C. (2007) Evaluation of Accuracy of Fine Needle Aspiration Cytology for Diagnosis of Canine Mammary Tummours: Comparative Features with Human Tumours. Cytopathology, 18, 191-196.

[13] Ensani, F., Enayati, L., Rajabiani, A., Omranipour, R., Alavi, N. and Mosaheb. S. (2013) Improved Detection of Metástases by Step Sectioning and Immuno-Histochemical Staining of Axillary Sentinel Nodes in Patients with Breast Carcinoma. Asian Pacific Journal of Cancer Prevention, 14, 5731-5734. http://dx.doi.org/10.7314/APJCP.2013.14.10.5731

[14] Schuman, S., Walker, G. and Avisar, E. (2011) Processing Sentinel Nodes in Breast Cancer: When and How Many. Archive Surgery, 146, 389-393. http://dx.doi.org/10.1001/archsurg.2011.29

[15] Santos, A.A., Lopes, C.C., Ribeiro, J.J., Martins, L.R., Santos, J.C., Amorim, I.F., Gärtner, F. and Matos, A.J. (2013) Identification of Prognostic Factors in Canine Mammary Malignant Tumours: A Multivariable Survival Study. BMC Veterinary Research, 9, 1. http://dx.doi.org/10.1186/1746-6148-9-1

[16] Matos, A.J.F., Lopes, C., Carvalheira, J., Santos, M., Rutteman, G.R. and Gärtner, F. (2006) E-Cadherin Expression. In Canine Malignant Mammary Tummours: Relationship to Other Clinic-Pathological Variables. Journal of Comparative Pathology, 134, 182-189. http://dx.doi.org/10.1016/j.jcpa.2005.10.004

[17] Pinheiro, L.G.P., Moraes, M.O., Soares, A.H., Lopes, A.J.T., Naguere, M.A.S.P., Gondim, F.A.L., Brandão, C.B., Nascimento, D.C.H., Soares, J.P.H. and Silva, J.M.M. (2003) Estudo experimental de linfonodo sentinela na mama de cadela com azul patente e Tecnécio Tc99m. Acta Cirúrgica Brasileira, 18, 514-517. http://dx.doi.org/10.1590/S0102-86502003000600006

[18] Melo, J.R.M. and Pinheiro, L.G.P. (2010) Linfonodo Sentinela: Importancia na cirurgia do cancer gástrico e perspectiva da aplicação de um modelo experimental em caninos. Arquivos Brasileiros de Cirurgia Digestiva, 23, 192-195. http://dx.doi.org/10.1590/s0102-67202010000300012

[19] Aquino, J.U., Pinheiro, L.G.P., Vasques, P.H.D., Rocha, J.I.X., Cruz, D.A., Beserra, H.E.O. and Cavalcante, R.V. (2012) Experimental Canine Model for Sentinel Lymph Node Biopsy in the Vulva Using Technetium and Patent Blue Dye. Acta Cirurgica Brasileira, 27, 102-108. http://dx.doi.org/10.1590/S0102-86502012000200002

[20] Brenet, O., Lalourcey, L., Queinnec, M., Dupoiron, D., Jayr, C., Rosay, H., Mavoungou, P., Monnin, D., Ancel, B., Maget, B., Louvier, N. and Malinovsky, J.M. (2013) Hypersensitivity Reactions to Patent Blue V in Breast Cancer Surgery: A Prospective Multicentre Study. Acta Anaestesiology Scandinavica, 57, 106-111. http://dx.doi.org/10.1111/aas.12003

[21] Cassali, G.D., Lavallle, G.E., de Nardi, A.B., Ferreira, E., et al. (2011) Consensus for the Diagnosis, Prognosis and Treatment of Canine Mammary Tumors. Brazilian Journal Veterinary Pathology, 4, 153-180.

[22] Misdorp, W. (2002) Tumors of the Mammary Gland. Blackwell, Ames.

[23] Schloppmann, S.F., Birner, P. and Stuner, P. (2001) Lymphatic Microvessel Density and Lymphovascular Invasion Assessed by Anti-Podoplanin Immunostaining in Human Breast Câncer. Anticancer Research, 21, 2351-2355.

[24] El-Gohary, Y.M, Metwally, G., Saad, R.S., Robinson, M.J., Mesko, T. and Poppiti, R.J. (2008) Prognostic Significance of Intratumoral and Peritumoral Lymphatic Density and Blood Vessel Density in Invasive Breast Carcinomas. American Journal of Clinical Pathology, 129, 578-586. http://dx.doi.org/10.1309/2HGNJ1GU57JMBJAQ

[25] Shibata, M.A., Ambati, J., Shibata, E., Yoshidome, K. and Harada-Shiba, M. (2012) Mammary Cancer Gene Therapy Targeting Lymphangiogenesis: VEGF-C siRNA and Soluble VEGF Receptor-2, a Splicing Variant. Medical Molecular Morphology, 45, 179-184. http://dx.doi.org/10.1007/s00795-012-0576-5

[26] Pereira, C.T., Marques, F.L.N., Williams, J., Martin, B.W. and Bombonato, P.P. (2008) ${ }^{99 M}$ Tc-Labeled Dextran for Mammary Lymphoscintigraphy in Dogs. Veterinary Radiology \& Ultrasound, 49, 487-491. http://dx.doi.org/10.1111/j.1740-8261.2008.00414.x

[27] Sorenmo, K.U., Rasotto, R., Zappulli, V. and Goldschmidt, M.H. (2011) Development, Anatomy, Histology, Lymphatic Drainage, Clinical Features, and Cell Differentiation Markers of Canine Mammary Gland Neoplasms. Veterinary Pathology, 48, 85-97. http://dx.doi.org/10.1177/0300985810389480 
[28] Szczubial, M. and Lopuszynski, W. (2011) Prognostic Value of Regional Lymphnode Status in Canine Mammary Carcinomas. Veterinary and Comparative Oncology, 9, 296-303. http://dx.doi.org/10.1111/j.1476-5829.2011.00268.x

[29] Goyal, A., Newcombe, R.G., Chhabra, A. and Mansel, R.E. (2006) Factors Affecting Failed Localization and FalseNegative Rates of Sentinela Node Biopsy in Breast Câncer Results of the ALMANAC Validation Phase. Breast Cancer Research Treatment, 99, 203-208. http://dx.doi.org/10.1007/s10549-006-9192-1

[30] Sobin, L.H. and Wittekind, C.H. (2002) TNM Classification of Malignant Tumours. Wiley, New York. 